\title{
Adaptive Droop-based Hierarchical Optimal Voltage Control Scheme for VSC-HVDC Connected Offshore Wind Farm
}

Huang, Sheng; Wu, Qiuwei; Liao, Wu ; Wu, Gongping; Li, Xueping; Wei, Juan

Published in:

IEEE Transactions on Industrial Informatics

Link to article, DOI:

10.1109/TII.2021.3065375,

Publication date:

2021

Document Version

Peer reviewed version

Link back to DTU Orbit

Citation (APA):

Huang, S., Wu, Q., Liao, W., Wu, G., Li, X., \& Wei, J. (2021). Adaptive Droop-based Hierarchical Optimal Voltage Control Scheme for VSC-HVDC Connected Offshore Wind Farm. IEEE Transactions on Industrial Informatics, 17(12), 8165 - 8176. https://doi.org/10.1109/TII.2021.3065375,

\section{General rights}

Copyright and moral rights for the publications made accessible in the public portal are retained by the authors and/or other copyright owners and it is a condition of accessing publications that users recognise and abide by the legal requirements associated with these rights.

- Users may download and print one copy of any publication from the public portal for the purpose of private study or research.

- You may not further distribute the material or use it for any profit-making activity or commercial gain

- You may freely distribute the URL identifying the publication in the public portal 


\title{
Adaptive Droop-based Hierarchical Optimal Voltage Control Scheme for VSC-HVDC Connected Offshore Wind Farm
}

\author{
Sheng Huang, Qiuwei Wu, Senior Member, IEEE, Wu Liao, Gongping Wu, Xueping Li, and Juan Wei
}

\begin{abstract}
An adaptive droop-based hierarchical optimal voltage control (DHOVC) scheme is proposed for voltage-source converter high-voltage-direct-current (VSC-HVDC) connected offshore wind farms (WFs). The wind turbines (WTs) and WF side VSC (WFVSC) are coordinated to minimize the voltage deviations of buses inside the WF from the nominal voltage and mitigate reactive power (Var) fluctuations of WTs. The model predictive control (MPC) is used to improve the performance of the DHOVC scheme during a certain predictive horizon. A hierarchical solution method based on the alternating direction method of multipliers (ADMM) is developed to reduce the calculation burden of the central controller while improving the information privacy protection. During the predictive horizon, the WTs and WFVSC are coordinated to achieve the near global optimal performance without global information. A WF with $32 \times 5$ MW WTs was used in the matlab/simulink to test the proposed DHOVC scheme.
\end{abstract}

Index Terms-alternating direction method of multipliers, droop curve, model predictive control, voltage control, wind farm.

\section{INTRODUCTION}

$\mathbf{I}$ $\mathrm{N}$ recent year, renewable energy has experienced rapid and sustainable development due to its advantage on economic advance and environmental protection. Among the renewable energies, offshore wind power has attracted increasing attention from academia and industry [1], [2]. For the offshore wind farms (WFs) far from onshore, the voltage source converter high-voltage direct current (VSC-HVDC) transmission system is preferred due to its advantages on flexible operation, economic benefits [3], [4], and its ability to maintain voltage and frequency in the isolated offshore WF grid [5].

Although the wind blows faster and more uniformly at sea than on land [6], the stochastic and strong fluctuation of wind energy also creates challenges to the offshore WF operation. In recent years, the voltage fluctuation problem caused by the intermittent active power generated from the wind turbines (WTs) has attracted more and more attention. To mitigate the negative voltage effects and enhance the operation

Manuscript received July 8, 2020; revised August 31, 2020; accepted Mar 07, 2021.

Corresponding author: Qiuwei Wu (e-mail: qw@elektro.dtu.dk).

S. Huang, W. Liao, G. Wu, X. Li and J. Wei are with College of Electrical and information engineering, Hunan University , Changsha 410082, China.(e-mail: huang98123@163.com, liaowu1988@hnu.edu.cn, gongping_ wu@hnu.edu.cn, 1xp1993@hnu.edu.cn, weijuanba@hnu.edu.cn).

Q. Wu is with Center for Electric Power and Energy (CEE), Department of Electrical Engineering, Technical University of Denmark (DTU), Kgs. Lyngby, 2800 Denmark. (e-mail: qw@elektro.dtu.dk). performance, the modern WFs are required to regulate the voltage of the buses inside WFs within a specific range [7].

The optimal voltage/Var control deals with finding a control law for the WF operation, which has an objective function to ensure a certain optimality criterion can be achieved. The optimal voltage/Var control has motivated a number of studies. References [8] proposed an model predictive control (MPC)based optimal control scheme to optimize the power injection of WTs during the normal and corrective modes, which can effectively minimize the voltage deviations of buses within the WF and improve the economic performance. An optimal power flow (OPF)-based Var dispatch strategy was proposed in [9]. The proposed strategy considers the power losses inside the WF and uses the voltage control capability of an offshore VSC-HVDC. To overcome the shortcomings of the centralized optimal control on computational efficiency of the central supervisor, communication cost, and the robustness of the control topology, the distributed/hierarchical control methods have been studied for the WF and microgirds optimal operation [10]- [14]. Reference [11] established the first systematic and pioneering distributed control framework to set up efficient and resilient microgrid clusters, providing a creative perspective on system operational flexibility. In [12], the active and Var control based on consensus protocol with a two-tier control structure was proposed. The control scheme is designed to achieve fair active power and Var sharing among multiple WFs. In [13], the consensus alternating direction method of multipliers (ADMM) is adopted to regulate the collector bus voltages of multiple WFs in a distributed manner, while the bus voltages inside each WF are regulated in a hierarchical manner. In [14], a distributed control scheme based on analytical target cascading algorithm is proposed for WFs. The WF controllers operate in parallel without the coordination of the central unit while achieving the optimal voltage regulation.

The distributed control methods highly rely on the communication technology. The communication delay and data integrity will affect the response speed of the control system and optimality of the solution. Besides, the above distributed control methods are essentially offline algorithms, wherein the optimal solution is applied until the iterations converge. The decentralized control method fully depends on local measurement without communication system and easy to implement, has been widely used in the power system [15]- [22]. In [5], a novel droop-based frequency regulation scheme was proposed for offshore WFs which is connected to a HVDC system. The WTs follow the droop curve to output Var equally without 
the requirement of the communications. In [16], a variable droop voltage control strategy was used in the WF. The aim is to reduce the voltage fluctuations at the point of connection (POC) by regulating the voltage-Var droop coefficients of the WTs based on their corresponding maximum Var capacity.

The decentralized control methods have been widely used in the microgrids. In [17], a novel descriptor system $H_{\infty}$ approach was proposed for VSC-based microgrids, which can regulate the voltage and frequency efficiently by using a hierarchical droop-based control structure. The communication time-delay is considered to improve the operation performance of the system. In [18], an adaptive droop control scheme was proposed for an isolated microgrid power system. The power sharing among the energy storage devices is achieved by using the dynamic droop factors. In [19], the voltage droop slope was tuned to compensate for the mismatch in the voltage drops across feeders by using communication links, which is inherently immune to delays in the communication links. An adaptive droop scheme was proposed in [20] for dc microgrids to overcome the non-linearity of the system. The aim is to eliminate the current sharing error of each unit in the microgrid. In [21], a noncooperative control problem of onboard pulsed power load in microgirds was formulated, which can achieve the near-optimal control without knowledge of system dynamics by using the neural network based control algorithm. In [22], a novel decentralized output constrained control algorithm was proposed for single-bus dc microgrids, the control algorithm can guarantee not only convergence but also bounded transient tracking errors.

According to the above analysis, with the increasing size of WFs, the central controller may fail to obtain the optimal solution in a certain control period to respond to the fast voltage fluctuations caused by the grid disturbance and variable wind speed. The communication delay in the distributed control method affects the response speed and optimality of the control system. Moreover, to the best of our knowledge, the existing droop control method for the WF operation can not obtain an optimal solution and there is no local algorithm that is guaranteed to solve the voltage optimization problem [23], [24]. To reduce the calculation burden of the central controller, impacts of the communication delay and improve the response speed to voltage fluctuations, this paper proposes an adaptive droop-based hierarchical optimal voltage control (DHOVC) scheme for the VSC-HVDC connected offshore WF. The DHOVC scheme aims to reduce the voltage deviation of the POC, medium voltage (MV) buses, and WT terminal from their nominal voltage while smoothing the Var fluctuations of the WTs. The proposed control scheme is operated in a hierarchical manner by using the ADMM algorithm to optimize voltage reference of the WF side VSC (WFVSC) and generate the optimal droop coefficients for the WTs during a certain predictive horizon. The voltage fluctuations caused by the droop coefficient at each prediction step are predicted and considered into the optimization problem by using the MPC method.

The main contribution of this paper is the design of the DHOVC scheme for the VSC-HVDC connected offshore WFs. Compared to the conventional centralized optimal control, the
Var of the WTs is regulated by following the droop curves instead of the dispatch command from the WF controller, implying the WT can fast respond to the voltage fluctuations without complex calculations. Compared to the distributed control method, the control period can be extended to reduce the impacts of the communication delay and calculation burden of the WF while ensuring excellent operating performance. With the ADMM algorithm, the calculation burden of the central controller of the WF can be further reduced efficiently while the information privacy of the WF is improved. During a certain predictive horizon, each WT can fast respond to the voltage fluctuations while achieving the near-global optimal operation performance without global information of the WF. Moreover, even the communication system fails, each WT can still work well according to the previously obtained droop coefficient if the wind condition does not change obviously, implying the better robustness and stability.

The rest of the paper is organized as follows. Section II gives the control architecture of the DHOVC scheme. The droop control-based MPC model is linearized in Section III. The optimization problem with droop control is described in Section IV. Finally, case study are shown and discussed in Section V, followed by the conclusions.

\section{Control Architecture}

\section{A. WF Topology}

A WF with a radial topology is shown in Fig. 1 [8]. The power generated by the WTs is collected by the MV collector system. There are several MV/HV transformers and $\mathrm{HV}$ transmission cables connected to the POC. The POC is connected to the WFVSC controlled bus through the main transformer. The WFVSC is responsible for energizing the WF. The power of the WF is collected at the POC and delivered to the external grid by using a VSC-HVDC system. Since a number of $\mathrm{MV}$ cables with the low $\mathrm{X} / \mathrm{R}$ ratio are used inside the WF, the fluctuating active power outputs of the WTs will result in the frequent voltage fluctuations of the buses.

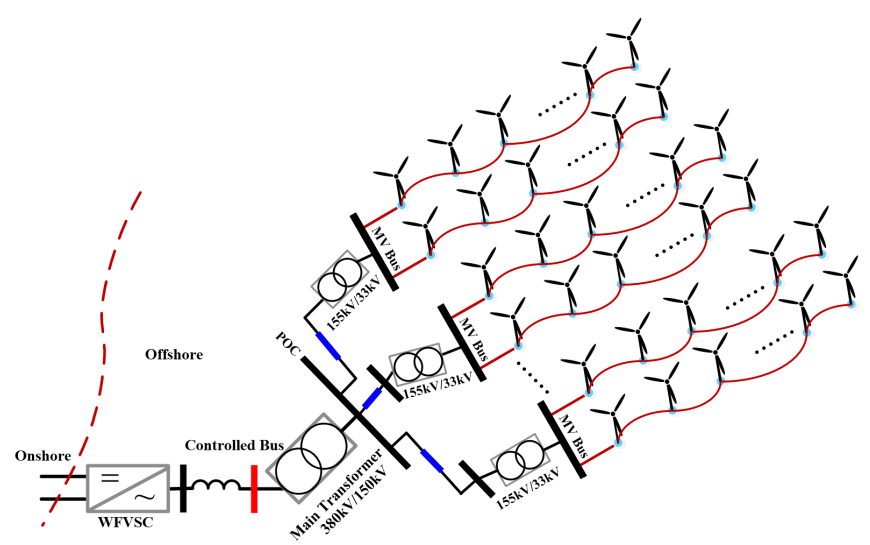

Fig. 1. Topology of a WF.

\section{B. Control Concept}

The control concept of the proposed DHOVC scheme is shown in Fig. 2. The control objective of the DHOVC scheme 
are to reduce the voltage deviation of the POC, MV buses, and WT terminal from their nominal voltage while smoothing the Var fluctuations of the WTs. The local controllers are equipped to the WFVSC and each WT. All controllers are connected through communication networks. The sensitivity calculation block is used to calculate the voltage sensitivity coefficients respect to the Var output of the WTs and controlled bus voltage, which needs the measurements from the WF and grid parameters. The MPC is adopted to formulate the voltage optimization problem with the droop control during each predictive horizon. The predictive horizon consists several prediction steps. At each prediction step, the voltage fluctuations caused by the intermittent wind power and Var injection of WTs is predicted to improve the accuracy of the predictive model. The optimal voltage reference of the WFVSC and the optimal droop coefficients of the WTs are generated and sent to local controllers during each predictive horizon. The WTs update the Var references according to their corresponding droop curves and local voltage measurements to fast respond to the voltage fluctuations.

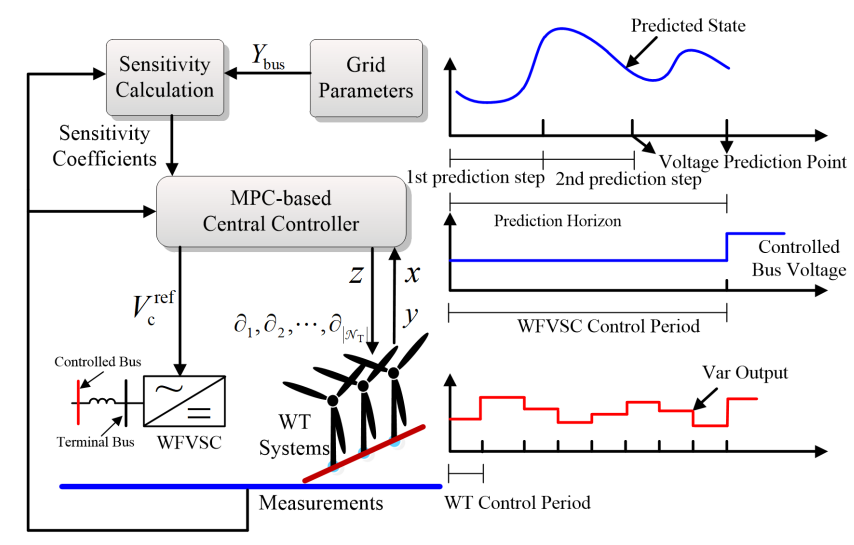

Fig. 2. Control framework.

\section{Wind FARM MODEl With DroOP CONTROL}

\section{A. WFVSC and WT model}

In a VSC-HVDC connected WF, the WFVSC is responsible for energizing the WF and maintaining stable frequency of the WF. The control method is described in [8] in detail. The terminal bus of the WFVSC is defined as the slack bus of the WF collector system. With the standard double-closed loop control structure of the WFVSC, the inner current loop can be approximated as a first-order lag function due to the fast dynamic behaviour. Since the communication distance inside the WF is relatively small compared to the large-scale power system, the communication delay from the WF controller to the WFVSC is small with fiber-optical communication. Thus, in order to simplify the model of the WFVSC, a first-order lag function is used to represent the communication delay of the WFVSC. Then, the incremental state-space model of the WFVSC considering the communication delay is,

$$
\Delta \dot{x}_{\mathrm{v}}=\boldsymbol{A}_{\mathrm{v}} \Delta x_{\mathrm{v}}+\boldsymbol{B}_{\mathrm{v}} \Delta u_{\mathrm{v}}
$$

where

$$
\begin{gathered}
\Delta x_{\mathrm{v}}=\left[\Delta V_{\mathrm{c}}^{\mathrm{ref} *}, \Delta V_{\mathrm{c}}, \Delta V_{\mathrm{c}}^{\mathrm{int}}, \Delta i_{\mathrm{sd}}\right]^{\mathrm{T}}, \Delta u_{\mathrm{t}}=V_{\mathrm{c}}^{\mathrm{ref}} \\
\boldsymbol{A}_{\mathrm{v}}=\left[\begin{array}{cccc}
-\frac{1}{T_{\mathrm{c}}} & 0 & 0 & 0 \\
0 & 0 & 0 & -\frac{1}{C_{\mathrm{f}}} \\
1 & -1 & 0 & 0 \\
-\frac{K_{\mathrm{p}}}{T_{\mathrm{i}}} & \frac{K_{\mathrm{p}}}{T_{\mathrm{i}}} & -\frac{K_{\mathrm{i}}}{T_{\mathrm{i}}} & -\frac{1}{T_{\mathrm{i}}}
\end{array}\right] \boldsymbol{B}_{\mathrm{v}}=\left[\begin{array}{c}
\frac{1}{T_{\mathrm{c}}} \\
0 \\
0 \\
0
\end{array}\right]
\end{gathered}
$$

where $T_{\mathrm{c}}$ is the time constant of the communication delay, $V_{\mathrm{c}}^{\text {ref }}$ is the voltage reference of the WFVSC controlled AC bus, which is generated in the central controller, $V_{\mathrm{c}}^{\text {ref* }}$ is the voltage reference obtained by the WFVSC after the communication delay, $V_{\mathrm{c}}$ is the voltage of the controlled bus, $K_{\mathrm{P}}$ and $K_{\mathrm{i}}$ are the proportional and integral gains of the PI regulator of the outer loop, respectively, $C_{\mathrm{f}}$ is the filter capacitance of the WFVSC, $i_{\mathrm{sd}}$ is the d-axis current when using the grid voltage orientation, $V_{\mathrm{c}}^{\text {int }}$ is the integral of the error between voltage reference and measurement of the WFVSC controlled bus, $T_{\mathrm{i}}$ is the time constant of the inner loop, and $\Delta$ denotes the incremental of variables.

In a modern WT system, the active power and Var outputs of the WTs can be independently regulated with power electronic converters. In the droop-based Var control, the control action can be divided into two steps. In the first step, the WT searches the Var reference by using a droop curve. The Var reference of the WT is obtained according to the error between the voltage measurement and rated voltage, which can be expressed as,

$$
Q_{\mathrm{wt}}^{\mathrm{ref}}=\min \left\{\max \left\{\alpha\left(V_{\mathrm{wt}}-V_{\text {rated }}\right), Q_{\min }\right\}, Q_{\max }\right\},
$$

where $Q_{\mathrm{wt}}^{\mathrm{ref}}$ is the Var reference of the WT, $Q_{\min }$ and $Q_{\max }$ are the minimum and maximum available Var of the WT, respectively, $\alpha$ is the droop coefficient, $V_{\mathrm{wt}}$ is the voltage measurement at the WT terminal bus, and $V_{\text {rated }}$ is the rated voltage. The WT provides Var support by following the droop curve while the WT tracking the maximal available wind power. In order to formulate the dynamic behavior and timedelay of the Var regulation of the WT in the second step, based on [25], we can get,

$$
\Delta Q_{\mathrm{wt}}=\frac{1}{1+s T_{\mathrm{Q}}} \Delta Q_{\mathrm{wt}}^{\mathrm{ref}}
$$

where $Q_{\mathrm{wt}}$ is the Var output measurement of the WT, and $T_{\mathrm{Q}}$ is the time constant. Then, we can obtain,

$$
\Delta \dot{Q}_{\mathrm{wt}}=-\frac{1}{T_{\mathrm{Q}}} \Delta Q_{\mathrm{wt}}+\frac{1}{T_{\mathrm{Q}}} \Delta Q_{\mathrm{wt}}^{\mathrm{ref}}
$$

\section{B. Wind Farm model}

Based on (1) and (4), the continuous state-space model of the WF can be written as,

$$
\Delta \dot{x}=\boldsymbol{A} \Delta x+\boldsymbol{B} \Delta u
$$

where

$\Delta x=\left[\Delta V_{\mathrm{c}}, \Delta V_{\mathrm{c}}^{\mathrm{int}}, \Delta i_{\mathrm{sd}}, \Delta Q_{\mathrm{wt}, 1}, \Delta Q_{\mathrm{wt}, 2}, \ldots, \Delta Q_{\mathrm{wt},\left|\mathcal{N}_{\mathrm{T}}\right|}\right]^{T}$ 


$$
\begin{gathered}
\Delta u=\left[\Delta V_{\mathrm{c}}^{\mathrm{ref}}, \Delta Q_{\mathrm{wt}, 1}^{\mathrm{ref}}, \Delta Q_{\mathrm{wt}, 2}^{\mathrm{ref}}, \ldots, \Delta Q_{\mathrm{wt},\left|\mathcal{N}_{\mathrm{T}}\right|}^{\mathrm{ref}}\right]^{T} \\
\boldsymbol{A}=\operatorname{diag}\left[\boldsymbol{A}_{\mathrm{V}},-\frac{1}{T_{\mathrm{Q}, 1}},-\frac{1}{T_{\mathrm{Q}, 2}}, \ldots,-\frac{1}{T_{\mathrm{Q},\left|\mathcal{N}_{\mathrm{T}}\right|}}\right] \\
\boldsymbol{A} \in \Re^{\left(3+\left|\mathcal{N}_{\mathrm{T}}\right|\right) \times\left(3+\left|\mathcal{N}_{\mathrm{T}}\right|\right)} \\
\boldsymbol{B}_{\mathrm{wf}}=\operatorname{diag}\left[\boldsymbol{B}_{\mathrm{V}}, \frac{1}{T_{\mathrm{Q}, 1}}, \frac{1}{T_{\mathrm{Q}, 2}}, \ldots, \frac{1}{T_{\mathrm{Q},\left|\mathcal{N}_{\mathrm{T}}\right|}}\right] \\
\boldsymbol{B} \in \Re^{\left(3+\left|\mathcal{N}_{\mathrm{T}}\right|\right) \times\left(1+\left|\mathcal{N}_{\mathrm{T}}\right|\right)}
\end{gathered}
$$

where $\mathcal{N}_{\mathrm{T}}$ denotes the set of WTs inside the WF. Then, the discrete state-space model can be derived,

$$
\Delta x(k+1)=\boldsymbol{A}_{\mathrm{d}} \Delta x(k)+\boldsymbol{B}_{\mathrm{d}} \Delta u(k)
$$

The discrete state space matrixes $\boldsymbol{A}_{\mathrm{d}}$ and $\boldsymbol{B}_{\mathrm{d}}$ can be calculated with the method in [26].

\section{MPC-based droop Control Optimization Problem Formu- lation}

In this subsection, the MPC-based droop control model is formulated. To transform the optimization problem to a convex problem, the nonlinear model with the polynomial of the droop coefficients is linearized. The Var of the WTs inside the WF are regulated by following the droop curve. Defined $Q_{\mathrm{wt}, \mathrm{i}}^{0}$ as the initial Var measurement of the $i$ th WT, the incremental Var with the droop control can be described as,

$$
\Delta Q_{\mathrm{wt}, i}^{\mathrm{ref}}=\left(V_{\mathrm{wt}, i}-V_{\mathrm{rated}}\right) \alpha_{i}-Q_{\mathrm{wt}, \mathrm{i}}^{0}
$$

In each predictive horizon, the voltage reference of the WFVSC is constant while the Var of the WTs are dynamically changed according to the droop curves. Define $\Delta u^{*}=\left[\Delta V_{\mathrm{c}}^{\text {ref }}, \alpha^{*}\right]^{T}, \alpha^{*}=\left[\alpha_{1}, \alpha_{2}, \cdots, \alpha_{\left|\mathcal{N}_{\mathrm{t}}\right|}\right]$, and $\Delta y=$ $\left[V_{\mathrm{s}}, \Delta Q_{\mathrm{wt}, 1}, \Delta Q_{\mathrm{wt}, 2}, \ldots, \Delta Q_{\mathrm{wt},\left|\mathcal{N}_{\mathrm{T}}\right|}\right]$, the discrete state-space WF model with local droop control can be rewritten as,

$$
\begin{aligned}
\Delta x_{\mathrm{d}}(k+1) & =\boldsymbol{A}_{\mathrm{d}} \Delta x(k)+\boldsymbol{B}_{\mathrm{d}} \Delta u(k), \\
& =\boldsymbol{A}_{\mathrm{d}} \Delta x(k)+\boldsymbol{B}_{\mathrm{d}} \boldsymbol{M}(k) \Delta u^{*}+\boldsymbol{B}_{\mathrm{d}} \boldsymbol{E}(k), \\
\Delta y(k) & =\boldsymbol{C} \Delta x(k) .
\end{aligned}
$$

where

$$
\begin{gathered}
\boldsymbol{M}(k)=\left[\begin{array}{ll}
1 & \\
& \boldsymbol{M}_{\mathrm{wt}}(k)
\end{array}\right] \boldsymbol{E}=\left[\begin{array}{c}
0 \\
\boldsymbol{F}
\end{array}\right] \\
\boldsymbol{C}=\left[\begin{array}{cccc}
\boldsymbol{C}_{\mathrm{v}} & \boldsymbol{C}_{\mathrm{wt}, 1} & \cdots & \boldsymbol{C}_{\mathrm{wt},\left|\mathcal{N}_{\mathrm{T}}\right|} \\
& 1_{1} & & \\
& \ddots & \\
& & 1_{\left|\mathcal{N}_{\mathrm{T}}\right|}
\end{array}\right] \\
\boldsymbol{C}_{\mathrm{v}}=-\left(\frac{\partial V_{\mathrm{c}}}{\partial V_{\mathrm{s}}}\right)^{-1}[-1,0,0], \\
\boldsymbol{C}_{\mathrm{wt}, i}=-\left(\frac{\partial V_{\mathrm{c}}}{\partial V_{\mathrm{s}}}\right)^{-1}\left(\frac{\partial V_{\mathrm{c}}}{\partial Q_{\mathrm{wt}, i}}\right), \quad \forall i \in \mathcal{N}_{\mathrm{T}}
\end{gathered}
$$

where $\frac{\partial V_{\mathrm{c}}}{\partial V_{\mathrm{s}}}$ and $\frac{\partial V_{\mathrm{c}}}{\partial Q_{\mathrm{wt}, i}}$ are the voltage sensitivity coefficients matrixes of the controlled bus with respect to the slack bus voltage and the $i$ th WT Var injection, respectively. More details can be found in [27]. $\boldsymbol{M}_{\mathrm{wt}}(k)$ is related to (7), which can be expressed as,

$$
\boldsymbol{M}_{\mathrm{wt}}(k)=\left[\begin{array}{lll}
V_{\mathrm{wt}, 1}(k)-V_{\text {rated }} & & \\
& \ddots & \\
& & V_{\mathrm{wt},\left|\mathcal{N}_{\mathrm{t}}\right|}(k)-V_{\text {rated }}
\end{array}\right]
$$

In the droop control-based MPC optimization problem formulation, $\boldsymbol{M}_{\mathrm{wt}}(k)$ should be updated in each predictive step with the voltage change. However, the WF controller only has the initial voltage measurements. $\boldsymbol{F}$ is also related to (7), which can be expressed as,

$$
\boldsymbol{F}=\left[\begin{array}{c}
-Q_{\mathrm{wt}, 1}^{0} \\
\vdots \\
-Q_{\mathrm{wt},\left|\mathcal{N}_{\mathrm{t}}\right|}^{0}
\end{array}\right]
$$

For the ind prediction step, the Var output change depends on the terminal voltage measurements of the WTs at the initial point of the $i$ nd prediction step. The coefficients of the droop curves are only optimized once in each predictive horizon with the initial voltage measurements. Therefore, the voltages of the WT at each control period should be predicted and formulated in the MPC optimization problem. For the $k$ nd prediction step, $\boldsymbol{M}_{\mathrm{wt}}(k)$ and can be expressed as,

$$
\begin{aligned}
\boldsymbol{M}_{\mathrm{wt}}(k) & =\operatorname{diag}\left[\boldsymbol{S}_{\mathrm{wt}}^{\mathrm{Q}} \Delta y(k)+\boldsymbol{S}_{\mathrm{wt}}^{\mathrm{P}} \Delta \boldsymbol{P}_{\mathrm{wt}}(k)+V_{\mathrm{wt}}^{0}-V_{\mathrm{rated}}\right] \\
& =\operatorname{diag}\left[\boldsymbol{S}_{\mathrm{wt}}^{\mathrm{Q}} \boldsymbol{C} \Delta x(k)+\boldsymbol{S}_{\mathrm{wt}}^{\mathrm{P}} \Delta \boldsymbol{P}_{\mathrm{wt}}(k)+V_{\mathrm{wt}}^{0}-V_{\mathrm{rated}}\right] \\
& =\operatorname{diag}\left\{\boldsymbol { S } _ { \mathrm { wt } } ^ { \mathrm { Q } } \boldsymbol { C } \left[\boldsymbol{A}_{\mathrm{d}} \Delta x(k-1)+\boldsymbol{B}_{\mathrm{d}} \boldsymbol{M}(k-1) \Delta u^{*}\right.\right. \\
& \left.\left.+\boldsymbol{B}_{\mathrm{d}} \boldsymbol{F}\right]+\boldsymbol{S}_{\mathrm{wt}}^{\mathrm{P}} \Delta \boldsymbol{P}_{\mathrm{wt}}(k)+V_{\mathrm{wt}}^{0}-V_{\text {rated }}\right\} \\
& =\cdots \cdots
\end{aligned}
$$

where $\boldsymbol{S}_{\mathrm{wt}}^{\mathrm{Q}}$ and $\boldsymbol{S}_{\mathrm{wt}}^{\mathrm{P}}$ are the voltage sensitivity coefficient matrixes with respect to the slack bus voltage and active power and Var injection of the WTs, respectively, and $\Delta \boldsymbol{P}_{\mathrm{wt}}(k)$ is the vector of the incremental active power $\Delta P_{\mathrm{wt}, i}$ at the $k \mathrm{nd}$ prediction step, $\Delta P_{\mathrm{wt}, i}(k)=P_{\mathrm{wt}, i}(k)-P_{\mathrm{wt}, i}^{0}$. In (10), the $\boldsymbol{M}_{\mathrm{wt}}(k)$ can be deduced back to the initial state space matrix with $x(0), \boldsymbol{B}_{\mathrm{wt}}(0)$, and initial voltage measurements $V_{\mathrm{wt}}^{0}$. However, $\boldsymbol{M}_{\mathrm{wt}}(k)$ consists of polynomial of $u^{*}$. It can not be formulated as a Quadratic programming $(\mathrm{QP})$ problem and is hard to be solved by the solvers. Therefore, the MPC-based discrete state-space WF model with local droop control should be reformulated. Taken the 2 nd prediction step as example,

$$
\begin{aligned}
\Delta x_{\mathrm{d}}(2) & =\boldsymbol{A}_{\mathrm{d}} \Delta x(1)+\boldsymbol{B}_{\mathrm{d}} \Delta u(1), \\
& =\boldsymbol{A}_{\mathrm{d}} \boldsymbol{B}_{\mathrm{d}} \boldsymbol{M}(0) \Delta u^{*}+\boldsymbol{A}_{\mathrm{d}} \boldsymbol{B}_{\mathrm{d}} F+\boldsymbol{B}_{\mathrm{d}} \Delta u(1) \\
\Delta y(2) & =\boldsymbol{C} \Delta x(2) .
\end{aligned}
$$

where $u(1)=\left[\Delta V_{\mathrm{c}}^{\mathrm{ref}}, u^{\dagger}(1)\right]^{T}$, and $u^{\dagger}(1)=\left[\Delta Q_{\mathrm{wt}, i}^{\mathrm{ref}}(1)\right.$, $\left.\Delta Q_{\mathrm{wt}, 2}^{\mathrm{ref}}(1), \cdots, \Delta Q_{\left|\mathcal{N}_{\mathrm{t}}\right|}^{\mathrm{ref}}(1)\right]^{T}$. According to (7) and (8), $u^{\dagger}(1)$ is obtained by the voltage conditions after the 1st prediction step. Since the accurate voltage measurements are not available during this time, the voltage conditions can only be predicted by using the sensitivity coefficients. Thus, $u^{\dagger}(1)$ can be calculated by, 


$$
\begin{aligned}
u^{\dagger}(1) & =\boldsymbol{M}_{\mathrm{wt}}(1) \alpha^{*}+\boldsymbol{F} \\
& =\operatorname{diag}\left\{\boldsymbol{S}_{\mathrm{wt}}^{\mathrm{Q}} \boldsymbol{C}\left[\boldsymbol{B}_{\mathrm{d}} \boldsymbol{M}(0) \Delta u^{*}+\boldsymbol{B}_{\mathrm{d}} \boldsymbol{F}\right]\right. \\
& \left.+\boldsymbol{S}_{\mathrm{wt}}^{\mathrm{P}} \Delta \boldsymbol{P}_{\mathrm{wt}}(0)+V_{\mathrm{wt}}^{0}-V_{\mathrm{rated}}\right\} \alpha^{*}+\boldsymbol{F}
\end{aligned}
$$

In (12), $\operatorname{diag}\left[S_{\mathrm{wt}}^{\mathrm{Q}} \boldsymbol{C} \boldsymbol{B}_{\mathrm{d}} \boldsymbol{M}(0) \Delta u^{*}\right] \alpha^{*}$ is quadratic with respect to $\alpha^{*}$, which can be approximated by using Taylor series expansion. Thus,

$$
\operatorname{diag}\left[S_{\mathrm{wt}}^{\mathrm{Q}} \boldsymbol{C} \boldsymbol{B}_{\mathrm{d}} \boldsymbol{M}(0) \Delta u^{*}\right] \alpha^{*} \approx \boldsymbol{T}(1) \Delta u^{*}+\boldsymbol{H}(1)
$$

where $\boldsymbol{T}(1)$ and $\boldsymbol{H}(1)$ are the matrixes related to the Taylor series expansion. Defining $\boldsymbol{R}(1)=\operatorname{diag}\left[S_{\mathrm{wt}}^{\mathrm{Q}} \boldsymbol{C}\left(\boldsymbol{B}_{\mathrm{d}} \boldsymbol{F}+\right.\right.$ $\left.\left.S_{\mathrm{wt}}^{\mathrm{P}} \Delta P_{\mathrm{wt}}(0)\right)+V_{\mathrm{wt}}^{0}-V_{\text {rated }}\right],(12)$ can be rewritten as,

$$
u^{\dagger}(1)=\boldsymbol{T}(1) \Delta u^{*}+\boldsymbol{R}(1) \alpha^{*}+\boldsymbol{H}(1)+\boldsymbol{F}
$$

In (14), the Var references of the WTs $u^{\dagger}(1)$ is decided by decision variables vectors $\Delta u^{*}$ and $\alpha^{*}$. According to (11), the decision variables at the 2 nd prediction step $u(1)$ can be obtained as,

$$
u(1)=\left[\boldsymbol{T}^{*}(1)+\boldsymbol{R}^{*}(1)\right] \Delta u^{*}+\boldsymbol{H}^{*}(1)+\boldsymbol{E}
$$

where

$$
\begin{gathered}
\boldsymbol{T}^{*}(1)=\left[\begin{array}{c}
T 0 \\
\boldsymbol{T}(1)
\end{array}\right] \boldsymbol{H}^{*}(1)=\left[\begin{array}{c}
0 \\
\boldsymbol{H}(1)
\end{array}\right] \\
\boldsymbol{R}^{*}(1)=\left[\begin{array}{cc}
0 & \cdots \\
\vdots & \boldsymbol{R}(1)
\end{array}\right] \\
T 0=[1,0,0,0, \ldots, 0], \quad T 0 \in \Re^{1 \times\left(1+\left|\mathcal{N}_{\mathrm{T}}\right|\right)}
\end{gathered}
$$

Then, (11) can be expressed as,

$$
\begin{aligned}
\Delta x_{\mathrm{d}}(2) & =\boldsymbol{W}_{\mathrm{d}}(1) u^{*}+\boldsymbol{E}_{\mathrm{d}}(1) \\
& =\left[\boldsymbol{A}_{\mathrm{d}} \boldsymbol{B}_{\mathrm{d}} \boldsymbol{M}(0)+\boldsymbol{B}_{\mathrm{d}} \boldsymbol{T}^{*}(1)+\boldsymbol{B}_{\mathrm{d}} \boldsymbol{R}^{*}(1)\right] \Delta u^{*} \\
& +\boldsymbol{A}_{\mathrm{d}} \boldsymbol{B}_{\mathrm{d}} \boldsymbol{F}+\boldsymbol{B}_{\mathrm{d}} \boldsymbol{H}^{*}(1)+\boldsymbol{B}_{\mathrm{d}} \boldsymbol{E} \\
\Delta y(2) & =\boldsymbol{C} \Delta x(2) .
\end{aligned}
$$

For each prediction step, the linearization of the discrete state-space WF model with local droop control is obtained in the same procedure, which is predicted according to the initial measurement and voltage sensitivity coefficient matrix. Thus, the discrete state-space WF model with local droop control can be linearized as,

$$
\begin{aligned}
\Delta x_{\mathrm{d}}(k+1) & =\boldsymbol{W}_{\mathrm{d}}(k) \Delta u^{*}+\boldsymbol{E}_{\mathrm{d}}(k) \\
\Delta y(k) & =\boldsymbol{C} \Delta x(k) .
\end{aligned}
$$

where

$$
\begin{gathered}
\boldsymbol{W}_{\mathrm{d}}(k)=\boldsymbol{A}_{\mathrm{d}} \boldsymbol{W}_{\mathrm{d}}(k-1)+\boldsymbol{B}_{\mathrm{d}} \boldsymbol{T}^{*}(k)+\boldsymbol{B}_{\mathrm{d}} \boldsymbol{R}^{*}(k) \\
\boldsymbol{E}_{\mathrm{d}}(k)=\boldsymbol{A}_{\mathrm{d}} \boldsymbol{E}_{\mathrm{d}}(k-1)+\boldsymbol{B}_{\mathrm{d}} \boldsymbol{H}^{*}(k)+\boldsymbol{B}_{\mathrm{d}} \boldsymbol{E} \\
\forall k \in 1,2,3, \ldots, N_{\mathrm{p}} \\
\boldsymbol{W}_{\mathrm{d}}(0)=\boldsymbol{B}_{\mathrm{d}} \boldsymbol{M}(0) \quad \boldsymbol{E}_{\mathrm{d}}(0)=\boldsymbol{B}_{\mathrm{d}} \boldsymbol{E}
\end{gathered}
$$

\section{Optimization Problem With Droop CONTROL}

\section{A. Cost Function}

When all WTs are operated in the maximum power point tracking (MPPT) mode, the proposed DHOVC scheme coordinates the WFVSC and WTs to reduce the voltage deviations of buses caused by the variation of the active power outputs. The first aim is to achieve an optimal voltage regulation of the WF. The voltage reference of the WFVSC and voltageVar droop coefficients of the WTs are the control variables of the optimization problem, which are optimized to reduce the voltage deviations of buses inside the WF from their nominal voltage. The control objective includes the POC, MV bus, and WT terminal bus, which are coordinated by weighting factor. Then, the control objective of the voltage regulation can be formulated as,

$$
\begin{gathered}
O b j_{1}=\min \sum_{k=1}^{N_{\mathrm{p}}}\left(\left\|\Delta V_{\mathrm{POC}}(k)\right\|_{W_{\mathrm{p}}}^{2}+\sum_{i=1}^{\left|\mathcal{N}_{\mathrm{C}}\right|}\left\|\Delta V_{\mathrm{MV}, i}(k)\right\|_{W_{\mathrm{M}}}^{2}\right. \\
\left.+\sum_{i=1}^{\left|\mathcal{N}_{\mathrm{wt}}\right|}\left\|\Delta V_{\mathrm{wt}, i}(k)\right\|_{W_{\mathrm{w}}}^{2}\right)
\end{gathered}
$$

$$
\begin{aligned}
\Delta V_{\mathrm{POC}}= & V_{\mathrm{POC}}^{0}+\frac{\partial V_{\mathrm{POC}}}{\partial y} \Delta y+\frac{\partial V_{\mathrm{POC}}}{\partial P_{\mathrm{wt}}} \Delta P \mathrm{wt}-V_{\mathrm{rated}} \\
\Delta V_{\mathrm{MV}, i}= & V_{\mathrm{MV}}^{0}+\frac{\partial V_{\mathrm{MV}, i}}{\partial y} \Delta y+\frac{\partial V_{\mathrm{MV}, i}}{\partial P_{\mathrm{wt}}} \Delta P_{\mathrm{wt}}-V_{\mathrm{rated}} \\
& \forall i \in \mathcal{N}_{\mathrm{M}} \\
\Delta V_{\mathrm{wt}, i}= & V_{\mathrm{wt}}^{0}+\frac{\partial V_{\mathrm{wt}, i}}{\partial y} \Delta y+\frac{\partial V_{\mathrm{wt}, i}}{\partial P_{\mathrm{wt}, i}} \Delta P_{\mathrm{wt}}-V_{\mathrm{rated}} \\
& \forall i \in \mathcal{N}_{\mathrm{wt}}
\end{aligned}
$$

where $\mathcal{N}_{\mathrm{C}}$ denotes the set of the MV buses, $\mathcal{N}_{\mathrm{wt}}$ denotes the set of the WTs, $\frac{\partial V_{\mathrm{POC}}}{\partial y}, \frac{\partial V_{\mathrm{MV}, i}}{\partial y}, \frac{\partial V_{\mathrm{wt}, i}}{\partial y}, \frac{\partial V_{\mathrm{POC}}}{\partial P_{\mathrm{wt}}}, \frac{\partial V_{\mathrm{MV}, i}}{\partial P_{\mathrm{wt}}}$, and $\frac{\partial V_{\mathrm{wt}, i}}{\partial P_{\mathrm{wt}}}$ are the voltage sensitivity matrixes. $\Delta y$ can be obtained from the MPC-based droop model (16). $W_{\mathrm{P}}, W_{\mathrm{M}}$, and $W_{\mathrm{w}}$ are the weighting factor of the POC, MV bus, and WT terminal bus voltages, respectively, which are used to coordinate the control performance of different buses. The second control objective is to minimize the Var fluctuations of the WTs,

$$
O b j_{2}=\min \sum_{k=1}^{N_{\mathrm{p}}} \sum_{i=1}^{\left|\mathcal{N}_{\mathrm{wt}}\right|}\left\|Q_{\mathrm{wt}, i}(k)-Q_{\mathrm{wt}, i}^{0}\right\|_{W_{\mathrm{R}}}^{2}
$$

where $Q_{\mathrm{wt}, i}^{0}$ is the initial Var measurement of the $i$ th WT, and $Q_{\mathrm{wt}, i}(k)$ is can be obtained from $\Delta y$ in (16), and $W_{\mathrm{R}}$ is the weighting factor. $O b j_{1}$ and $O b j_{2}$ can be formulated as a standard QP problem. Then the total cost function can be obtained as,

$$
O b j_{\text {total }}=O b j_{1}+O b j_{2}
$$

\section{B. Constraint}

Firstly, the controlled voltage of the WFVSC cannot violate the minimum and maximum voltage limits,

$$
V_{\mathrm{c}}^{\min } \leq V_{\mathrm{c}} \leq V_{\mathrm{c}}^{\max } .
$$


where $V_{\mathrm{c}}^{\min }$ and $V_{\mathrm{c}}^{\max }$ are the minimum and maximum voltages of the controlled bus, respectively. Secondly, since the measured voltage and the droop coefficient determine the Var output of each WT, the constraints for the $\alpha$ should ensure that the Var injections of the WTs will not violate the available Var limits. Thus, we can get,

$$
\frac{Q_{i}^{\min }}{V_{i}-V_{\text {rated }}} \leq \alpha_{i} \leq \frac{Q_{i}^{\max }}{V_{i}-V_{\text {rated }}}, \quad \forall i \in \mathcal{N}_{\mathrm{T}}
$$

where $Q_{i}^{\min }$ and $Q_{i}^{\max }$ are the minimum and maximum available Var of the $i$ th WT, which can be calculated dynamically according to the active power outputs of the WTs.

\section{Stability Analysis}

According to (8), the recurrence relation that describes how the bus voltage magnitudes evolve with time can be written as,

$$
\begin{aligned}
\boldsymbol{V}_{\mathrm{wf}}(k+1) & =\boldsymbol{S}_{\mathrm{wt}}^{\mathrm{Q}} \Delta Q_{\mathrm{wf}}(k)+\boldsymbol{S}_{\mathrm{vsc}} \Delta V_{\mathrm{s}}(k)+V_{\mathrm{wf}}(k) \\
& =\boldsymbol{S}_{\mathrm{wt}}^{\mathrm{Q}}\left[\operatorname{diag}\left(\boldsymbol{V}_{\mathrm{wf}}(k)-\boldsymbol{V}_{\mathrm{rated}}\right) \alpha^{*}-\boldsymbol{F}\right] \\
& +\boldsymbol{S}_{\mathrm{vsc}} \Delta V_{\mathrm{s}}(k)+\boldsymbol{V}_{\mathrm{wf}}(k)
\end{aligned}
$$

Eq. (24) can be further rewritten as,

$$
\begin{aligned}
\boldsymbol{V}_{\mathrm{wf}}(k+1) & =\left(\boldsymbol{I}+\operatorname{diag}\left(\alpha^{*}\right) \boldsymbol{S}_{\mathrm{wt}}^{\mathrm{Q}}\right) \boldsymbol{V}_{\mathrm{wf}}(k) \\
& +\boldsymbol{S}_{\mathrm{vsc}} \Delta V_{\mathrm{s}}(k)-\operatorname{diag}\left(\alpha^{*}\right) \boldsymbol{S}_{\mathrm{wt}}^{\mathrm{Q}} \boldsymbol{V}_{\text {rated }}-\boldsymbol{S}_{\mathrm{wt}}^{\mathrm{Q}} \boldsymbol{F}
\end{aligned}
$$

where $\boldsymbol{V}_{\mathrm{wf}}=\left[V_{1}, V_{2}, \cdots V_{\left|\mathcal{N}_{\mathrm{d}}\right|}\right]^{\mathrm{T}}, \mathcal{N}_{\mathrm{d}}$ denotes the set of the nodes inside the WF except the slack bus and controlled bus, $\boldsymbol{S}_{\mathrm{vsc}} \in \mathcal{R}^{\left|\mathcal{N}_{\mathrm{d}}\right| \times 1}$ is the voltage sensitivity matrix with respect to the slack bus voltage. Eq. (25) is a discrete time-invariant system, affected by droop coefficients $\alpha^{*}$ and WFVSC controlled voltage $V_{\mathrm{s}} . \boldsymbol{S}_{\mathrm{vsc}} \Delta V_{\mathrm{s}}$ is bounded due to the constraint (22), $\operatorname{diag}\left(\alpha^{*}\right) \boldsymbol{S}_{\mathrm{wt}}^{\mathrm{Q}} \boldsymbol{V}_{\text {rated }}$ is bounded due to the constraints (23), and $\boldsymbol{S}_{\mathrm{wt}}^{\mathrm{Q}} \boldsymbol{F}$ is a constant matrix. In order to ensure the stability of the system, $\boldsymbol{V}_{\mathrm{wf}}(k)$ remains bounded for all $k$. The eigenvalues of $\left(\boldsymbol{I}+\operatorname{diag}\left(\alpha^{*}\right) \boldsymbol{S}_{\mathrm{wt}}^{\mathrm{Q}}\right)$ must lie within the unit circle, i.e., $\sigma_{i}\left|\left(\boldsymbol{I}+\operatorname{diag}\left(\alpha^{*}\right) \boldsymbol{S}_{\mathrm{wt}}^{\mathrm{Q}}\right)\right| \leq 1, \forall i$, where $\sigma_{i}\left(\boldsymbol{I}+\operatorname{diag}\left(\alpha^{*}\right) \boldsymbol{S}_{\mathrm{wt}}^{\mathrm{Q}}\right)$ denotes the $i$ th eigenvalue of $\boldsymbol{I}+\operatorname{diag}\left(\alpha^{*}\right) \boldsymbol{S}_{\mathrm{wt}}^{\mathrm{Q}}$. Thus, $\alpha^{*}$ must meet the constraints,

$$
-\min \frac{2 \operatorname{Re} \lambda_{i}}{\left|\lambda_{i}^{2}\right|}<\alpha^{*}<0
$$

where $\lambda_{i}=\operatorname{Re} \lambda_{i}+j \operatorname{Im} \lambda_{i}$ denotes the $i$ th eigenvalue of $\boldsymbol{S}_{\mathrm{wt}}^{\mathrm{Q}}$ [28], [29].

\section{ADMM-based Hierarchical Solution}

Eq. (21) with constraints is a centralized optimization problem. With the WF size increasing, the increased calculation burden will increases the calculation time and impacts the control performance consequently. Therefore, a fast solution method is needed to generate the optimal droop coefficients of the WTs. The optimization problem is a standard QP problem with the decision variable $\Delta u^{*}$, which can be presented in a compact QP form as,

$$
\begin{gathered}
\min _{x} \Phi(x)=\frac{1}{2}\left(\Delta u^{*}\right)^{T} \boldsymbol{H} \Delta u^{*}+\boldsymbol{g}^{T} \Delta u^{*} \\
\text { s.t. } \quad \Delta \underline{u}^{*} \leq \Delta u^{*} \leq \Delta \bar{u}^{*}
\end{gathered}
$$

where $\boldsymbol{H} \succeq 0, \boldsymbol{H} \in \Re^{n \times n}$ and $\boldsymbol{g} \in \Re^{n \times 1}, \Delta \underline{u}^{*}$, and $\Delta \bar{u}^{*}$ denotes the lower and upper limits of $\Delta u^{*}$, and $n=1+\left|\mathcal{N}_{\mathrm{wt}}\right|$. To further improve the respond speed of the WF as much as possible, the ADMM-based hierarchical solution method is used to decompose the centralized optimization problem. The augmented Lagrangian $\mathcal{L}^{\mathrm{ADMM}}$ can be expressed as,

$$
\begin{gathered}
\mathcal{L}^{\mathrm{ADMM}}=\Phi(x)+y^{T}(x-z)+\frac{\rho}{2}\|x-z\|_{2}^{2} \\
\text { s.t. } \quad \Delta \underline{u}^{*} \leq \Delta u^{*} \leq \Delta \bar{u}^{*}
\end{gathered}
$$

where $y$ is the dual variables vector, and $\rho>0$ is the augmented Lagrangian parameter. Defined $x=\left[x_{1}, x_{2}, \ldots, x_{n}\right]$ as the local variables, which are related to the droop coefficients of the WTs and optimized in each local controller in parallel, $z=\left[z_{1}, z_{2}, \ldots, z_{n}\right]$ as the global variables, which are also related to the droop coefficients of the WTs and optimized in the central controller of the WF, and $\boldsymbol{I}$ as the identity matrix. The steps of the ADMM-based solution are listed in Table. I.

TABLE I

Steps of ADMM-BASEd Solution Method

$\begin{array}{ll}\text { Step } 1 & \text { Initialize: } \\ & x^{[1]}=0, z^{[1]}=0, y^{[1]}=0\end{array}$

Step 2 Update $z$ : The WF controller minimizes augmented Lagrangian $\mathcal{L}^{\mathrm{ADMM}}$ without constraints to obtain $z$ as,

$$
z^{[k+1]}=-\left(\boldsymbol{H}+\rho^{[k]} \boldsymbol{I}\right)\left(g-\rho x^{[k]}+y^{[k]}\right)
$$

Step 3 Update $x$ : The central controller sends the $z_{i}$ to its corresponding WT. The local variables are obtained by solving a simple augmented Lagrangian function with local constraints,

$$
x_{i}^{[k+1]}=\underset{x_{i}}{\arg \min } y_{i}^{\mathrm{T}[r]}\left(x_{i}-z_{i}^{[r+1]}\right)+\frac{\rho_{i}}{2}\left\|\left(x_{i}-z^{[r+1]}\right)\right\|_{2}^{2}
$$$$
\text { s.t. } \underline{x}_{i} \leq \Delta x_{i} \leq \Delta \bar{x}_{i}
$$

Step 4 Update $y$ :

$$
y_{i}^{[r+1]}=y_{i}^{[r+1]}+\rho\left(x_{i}^{[r+1]}-z_{i}^{[r+1]}\right)
$$

Step 5 Convergence check: Define the primal residuals as $h^{[r]}=$ $x^{[r]}-z^{[r]}$ and the dual residuals as $j^{[r]}=\left(z^{[r]}-z^{[r-1]}\right)$, then the iteration will stop when

$\left\|h^{[r]}\right\|^{2} \leq \epsilon^{\text {pri }} \cap\left\|j^{[r]}\right\|^{2} \leq \epsilon^{\text {dual }}$, where $\epsilon^{\text {pri }}$ and $\epsilon^{\text {dual }}$ are constants for the feasibility tolerances of the primal and dual feasibility conditions, respectively.

The ADMM algorithm is an iterative algorithm. When the global variables and local variables converge, each WT can obtain the optimal droop coefficient according to the converged local variable generated in its corresponding local controller.

\section{CASe Study}

\section{A. Test System}

In this section, a WF with $32 \times 5 \mathrm{MW}$ WTs is used to verify the effectiveness in the control performance with the DHOVC scheme. The WF consists of two MV bus. Each MV bus is connected by two feeders. For each feeder, eight 
WTs are placed with $4 \mathrm{~km}$ distance. The WF is tested in Matlab/simulink with the full nonlinear AC power flow environment. The WF operation performances with the proposed DHOVC scheme are compared to two other control schemes, which are the PI-based control scheme and centralized optimal voltage control (COVC) scheme [8]. The control action of the COVC scheme is carried out every second. In the PI-based control scheme, the control objective is to maintain the voltage of the POC stable only. A PI controller is adopted to obtain the total Var reference of the WTs, The Var references of the WTs are dispatched to the WTs based on a proportional distribution (PD) control scheme.

\section{B. Control Performance}

Fig. 3 shows the available wind power of the WF. Since the WF is operated in the MPPT mode, the active power output of the WF tracks the available wind power during the whole simulation time.

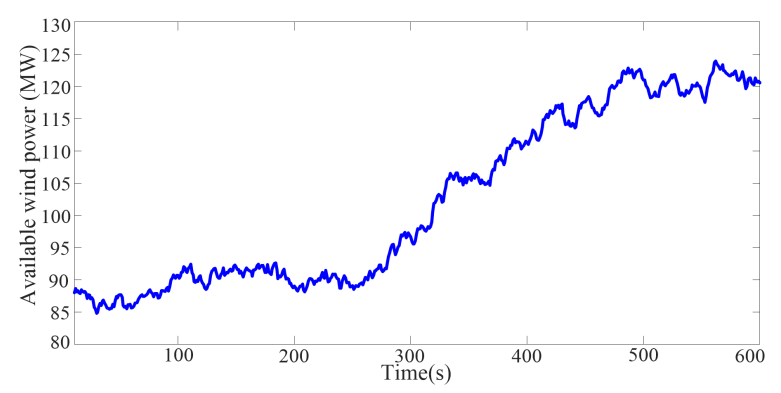

Fig. 3. Available wind power of WF.

The DHOVC scheme is carried out every 2 seconds to update the voltage reference of the WFVSC and droop coefficients of the WTs, $N_{\mathrm{p}}=2$. The update rate of WTs is set as $0.1 \mathrm{~s}$ based on the droop curves. The voltage performance of the POC is shown in Fig. 4. Since the PI-based control scheme only focus on maintaining the POC voltage stable, which shows the advantage on POC voltage regulation among the three control schemes. The voltage with the PI control scheme can be maintained at 1 p.u. efficiently during the whole simulation time. The voltage of the POC with the DHOVC and COVC schemes are similar, which fluctuate around 1.007 p.u. from $0 \mathrm{~s}$ to $300 \mathrm{~s}$. From $300 \mathrm{~s}$ to $600 \mathrm{~s}$, the voltage decrease to below 1.003 p.u.. Fig. 5 shows the voltages of the MV bus with the three control schemes. From $0 \mathrm{~s}$ to $300 \mathrm{~s}$, the voltages with the three control schemes are similar, which are maintained at around 0.99 p.u.. From 300 s to 600 $\mathrm{s}$, the voltage with the PI control scheme ascends to about 0.996 p.u. while those with the DHOVC and COVC schemes decreases to around 0.985 p.u. to 0.988 p.u.. The difference of the voltage performance between the PI control scheme and other two schemes is caused by the differences of the control objectives of the three control schemes. The aim of the PI control scheme only focus on the POC voltage regulation, which does not consider the WT terminal bus voltage. The aims of the DHOVC and COVC schemes take the voltage of both POC, MV, and WT terminal buses into consideration to achieve a global optimal control of the WF.

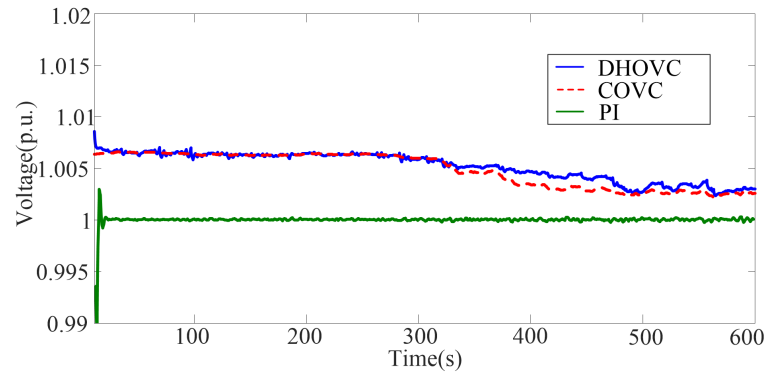

Fig. 4. Voltage of POC.

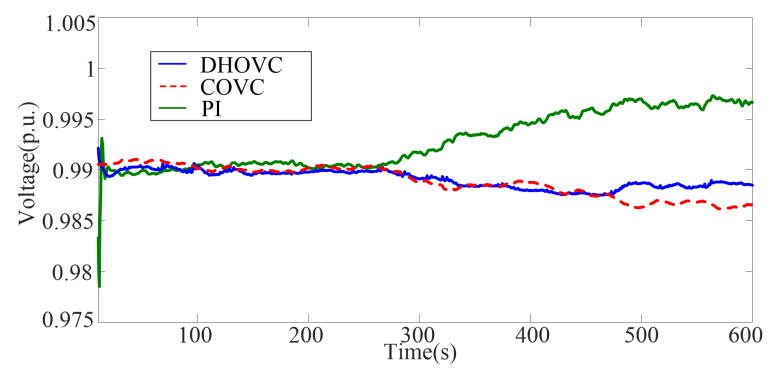

Fig. 5. Voltage of MV bus1.

Fig. 6 shows the voltage performances of WT8 with the three control schemes. WT8 is the last WT of the first feeder which has the highest risk to violate the voltage threshold. The voltage of the WT8 terminal bus with the DHOVC and COVC schemes show the superiority compared to those with the PI control scheme. From $0 \mathrm{~s}$ to $300 \mathrm{~s}$, the voltages with the DHOVC and COVC schemes are similar, which are kept at around 1.02 p.u.. For the PI control scheme, the voltage is kept at about 1.038 p.u. There are approximately 0.018 p.u. differences. After $300 \mathrm{~s}$, the voltage rises to about 1.06 p.u. with the active power output increasing while the voltage with the DHOVC and COVC schemes increasing to approximately 1.028 p.u.. There are 0.032 p.u. difference between the PI control scheme and other two control schemes.

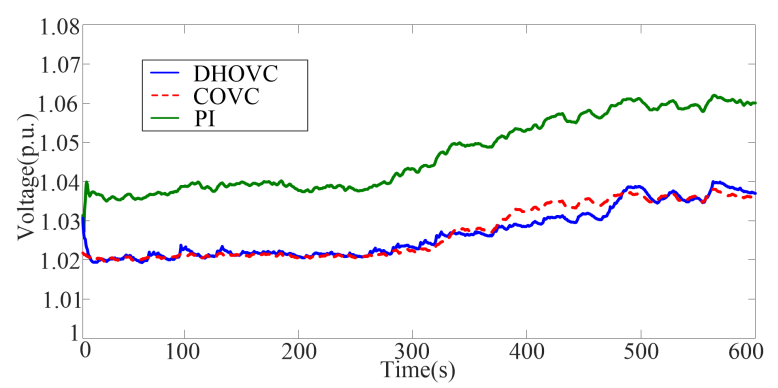

Fig. 6. Voltage of WT8 terminal bus.

In order to show the global optimal performance of the DHOVC scheme, Fig. 7 shows the total voltage deviation from the rated voltage. The overall voltage performance with the DHOVC and COVC schemes show the superiority compared to those with the PI control. From $0 \mathrm{~s}$ to $300 \mathrm{~s}$, the overall voltage with the DHOVC scheme is similar as those with the COVC scheme. From $300 \mathrm{~s}$ to $480 \mathrm{~s}$, the overall voltage with the DHOVC is better than those with the COVC scheme, 
TABLE II

THE COMPARISON OF AVERAGE VOLTAGE DEVIATION WITH DIFFERENT PREDICTIVE HORIZON

\begin{tabular}{lllllllll}
\hline & $30-100 \mathrm{~s}$ & $101-200 \mathrm{~s}$ & $201-300 \mathrm{~s}$ & $301-400 \mathrm{~s}$ & $401-500 \mathrm{~s}$ & $501-600 \mathrm{~s}$ & total & Reduce percentage \\
\hline PI control & 0.4230 & 0.4544 & 0.4542 & 0.5659 & 0.6660 & 0.6967 & 0.5497 & \\
COVC & 0.2938 & 0.2972 & 0.2983 & 0.3518 & 0.4252 & $0.4333 \mathrm{~s}$ & 0.3529 & $-35.80 \%$ \\
DHOVC $(\mathrm{Np}=2)$ & 0.2926 & 0.3007 & 0.3020 & 0.3423 & 0.3937 & 0.4457 & 0.3490 & $-36.51 \%$ \\
DHOVC $(\mathrm{Np}=3)$ & 0.2989 & 0.3098 & 0.3119 & 0.3624 & 0.4167 & 0.4586 & 0.3629 & $-33.98 \%$ \\
DHOVC $(\mathrm{Np}=4)$ & 0.3035 & 0.3168 & 0.3232 & 0.3742 & 0.4326 & 0.4669 & 0.3730 & $-32.14 \%$ \\
DHOVC $(\mathrm{Np}=5)$ & 0.3097 & 0.3197 & 0.3315 & 0.3829 & 0.4442 & 0.4737 & 0.3804 & $-30.80 \%$ \\
\hline
\end{tabular}

which has around 0.05 p.u. difference. From 480 s to 600 $\mathrm{s}$, the overall voltage with the COVC scheme and DHOVC scheme are similar.

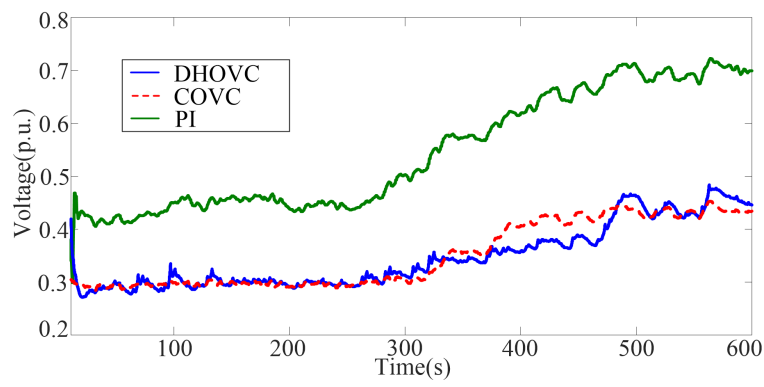

Fig. 7. Overall voltage deviation of WF.

Fig. 8 shows the droop coefficient of the WT14, which is the sixth WT of the second feeder. From $0 \mathrm{~s}$ to $300 \mathrm{~s}$, the droop coefficient is varied between -4.5 to -3.5 . From $300 \mathrm{~s}$ to $600 \mathrm{~s}$, since the active power outputs of WTs increase, the available Var of WT decreases with the rated capacity limits. The droop coefficient of WT14 increases to around -1.5 gradually. Fig. 9 shows the Var output of WT14. The performance with the DHOVC is similar as those with the COVC scheme, which only has approximately 0.1 MVar difference.

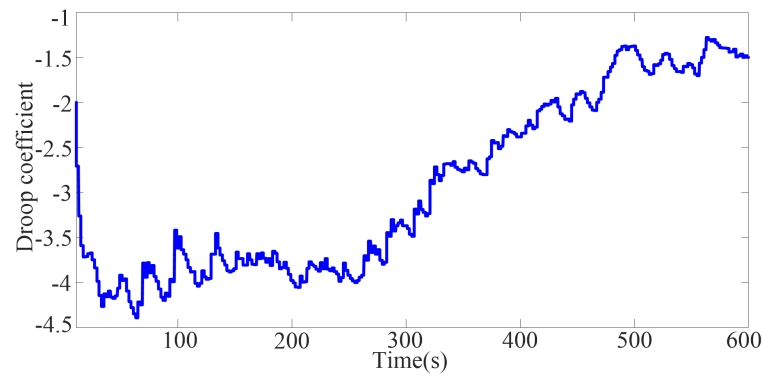

Fig. 8. Droop coefficient of WT14.

The control schemes have been tested with the detailed nonlinear DFIG model. Fig. 10(a) shows the rotor speeds of WT8 with the DHOVC and COVC schemes. The rotor speed with the DHOVC scheme is same as the ones with the COVC scheme. From 0 to $300 \mathrm{~s}$, the rotor speed of WT8 varies between 0.93 p.u. and 0.95 p.u. according to the active power reference and wind speed. From $300 \mathrm{~s}$ to 600 $\mathrm{s}$, the rotor speed increases gradually with the active power reference increasing. The rotor speed of WT8 changes from the sub-synchronous speed to the super-synchronous speed. The

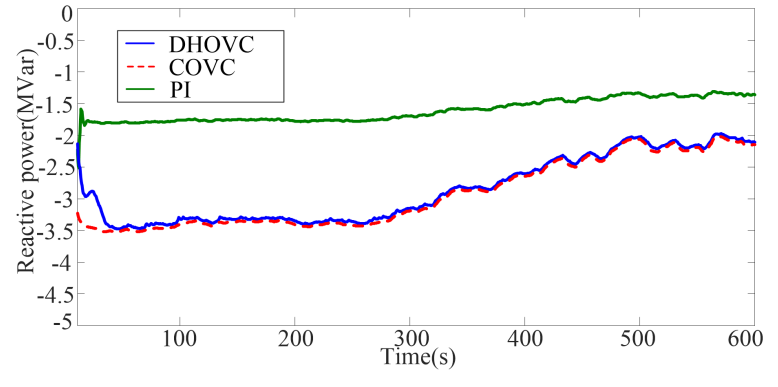

Fig. 9. Var output of WT14.

electromagnetic torques of WT8 with the DHOVC and COVC schemes are shown in the Fig. 10(b). The performances with the two control schemes are similar because the active power references are same. Fig. 11 shows the dq-axis currents of WT8 stator. The q-axis currents with the two control schemes are same, which correspond to the active power output of WT8 stator. The d-axis currents correspond to the reactive power output of WT8 stator, which decreases with the increasing qaxis current due to the WT capacity limit.

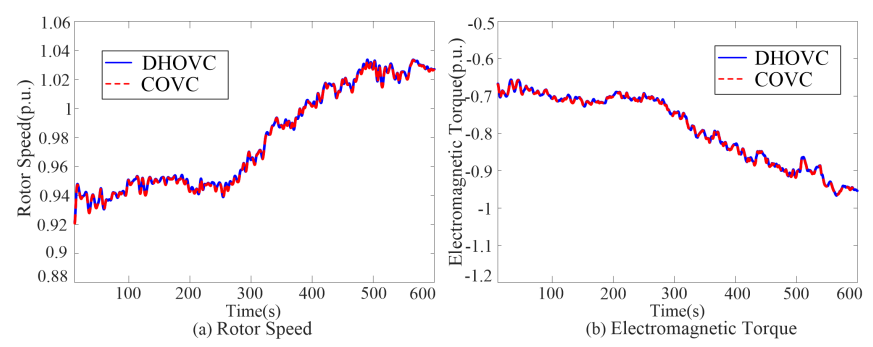

Fig. 10. Rotor speeds and Electromagnetic torques of WT8.

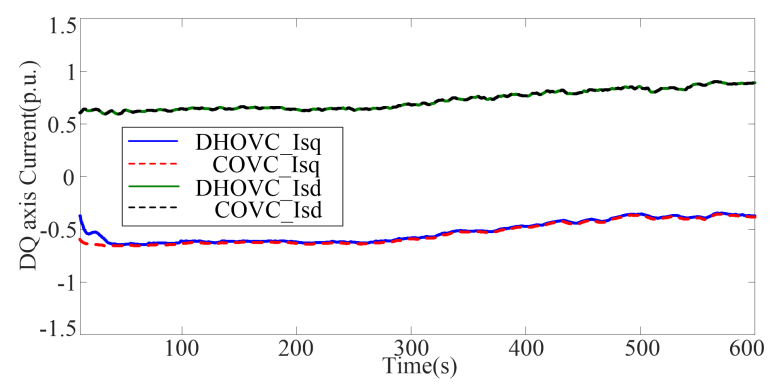

Fig. 11. dq-axis currents of WT8 stator.

The overall voltage deviations of DHOVC with different prediction horizons are also compared to the COVC and PI 
control schemes. The prediction horizon are set to 2, 3, 4, and $5 \mathrm{~s}$. The time of the prediction step is set as $1 \mathrm{~s}$. The overall voltage deviation of the WF with different prediction horizon is shown in Fig. 12. From $0 \mathrm{~s}$ to $280 \mathrm{~s}$, since the wind power fluctuates under relatively stable conditions, the performances with the different prediction horizons are similar. After around $300 \mathrm{~s}$, since the wind power increases gradually, the shorter the predictive horizon, the better the control performance. However, the overall voltage deviations with different prediction horizon are also better than those with the conventional PI control scheme.

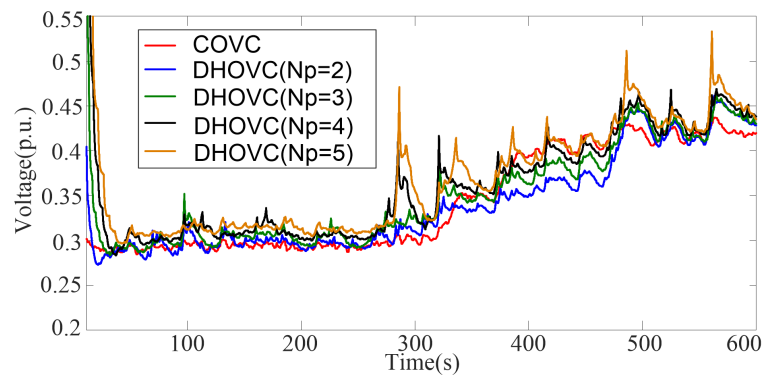

Fig. 12. Overall voltage deviation of the WF with different time scale.

The comparison of the average voltage deviation with the different prediction horizon during different period are listed in Table. I. The total average voltage deviation with the DHVOC $(\mathrm{Np}=2)$ is better than those with the COVC scheme. The total average voltage deviations of the DHOVC with the different prediction horizons have more than $30 \%$ percentage of reduction compared to the conventional PI control scheme. Moreover, with the ADMM method, the central controller only solve an simple optimization problem without constraints while the constraints are solved in the WT local controllers, the calculation burden can be further reduced when the WF consists of hundreds of WTs. The exchanged information between the central controller and WT local control is $x, z$, and $y$ instead of the actual measurements and references. The protection of the information privacy is improved compared to the PI-based and COVC control schemes.

In order show the robustness of the DHOVC scheme, a communication failure is set at WT8 at $200 \mathrm{~s}$. When the WT8 cannot receive the updated optimal droop coefficient, WT8 uses the previous obtained droop coefficient to generates the Var reference. The WT8 terminal voltage with the DHOVC scheme do not have significant voltage fluctuations when WT8 has a communication failure. The voltage performances with the COVC scheme become to worse when WT8 has a communication failure. The voltage of WT8 terminal increases to 1.025 p.u.. It is because that the WT8 cannot obtain the Var reference from the WF central controller. The comparison of the voltage performance with the DHOVC and COVC schemes under a communication failure is shown in Fig. 13.

Fig. 14 shows the voltage of WT8 terminal bus under the communication failure of the central controller. At $200 \mathrm{~s}$, a communication failure occurs at the central controller of the WF. The WT8 terminal voltage with the COVC scheme increases to around 1.1p.u.. The WTs have the risks to be

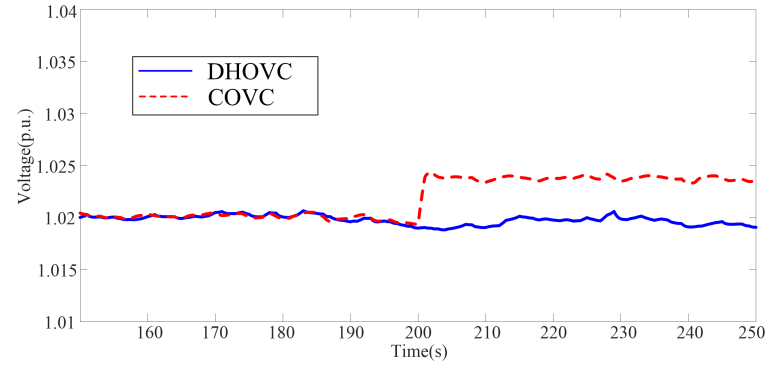

Fig. 13. Voltage of WT8 terminal bus under communication failure of WT8.

tripped. With the DHOVC scheme, all WTs uses the previous obtained droop coefficient to generates the Var reference while the WFVSC using the previous obtained voltage references to regulate the controlled bus. When the failure occurs, the voltage with the DHOVC scheme is stable from 200 to $210 \mathrm{~s}$. From 210 to $250 \mathrm{~s}$, the WT8 terminal voltage with the DHOVC scheme increases to around 1.03 p.u.. The voltages with the DHOVC scheme can be kept within the feasible range under the communication failure of the central controller, which is much better than those with the COVC scheme.

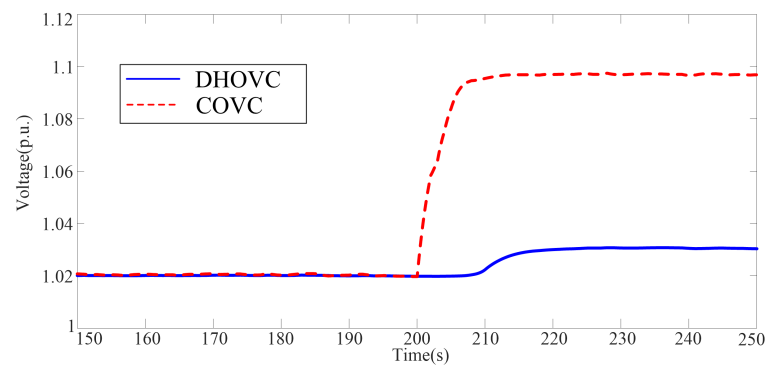

Fig. 14. Voltage of WT8 terminal bus under communication failure of central controller.

To show the response to different line impedance, the distances between the POC and the MV bus are set as 50 $\mathrm{km}$ and $100 \mathrm{~km}$, respectively. Fig. 15(a) shows the voltage of WT8 terminal with the DHOVC and COVC schemes. The voltage deviation with the $100 \mathrm{~km}$ distance is larger than those with the $50 \mathrm{~km}$ distance. With the distance between the MV bus and POC extending, the voltage deviation with the DHOVC control scheme is better than those with the COVC scheme. Fig. 15(b) shows the total voltage deviation from the rated voltage. The total voltage deviation with the $100 \mathrm{~km}$ distance fluctuates between 0.7 p.u. to 0.8 p.u.. The total voltage deviation with the $50 \mathrm{~km}$ distance fluctuates between 0.4 p.u. to 0.5 p.u.. Besides, the total voltage deviation of the WF with the DHOVC scheme shows the superiority compared to those with the COVC scheme.

The coordination of three WFs has been tested. The POCs of the three WFs are connected to a common VSC-HVDC system with the $30 \mathrm{~km}, 40 \mathrm{~km}$, and $50 \mathrm{~km}$ distance, respectively. The POC and the total voltage deviation of the three WFs are shown in the Fig. 16(a) and Fig. 16(b). In Fig. 16, the POC voltages of the three WFs are regulated within the feasible range with the DHOVC scheme. The total voltage deviation of the three WFs are different due to the different distance 


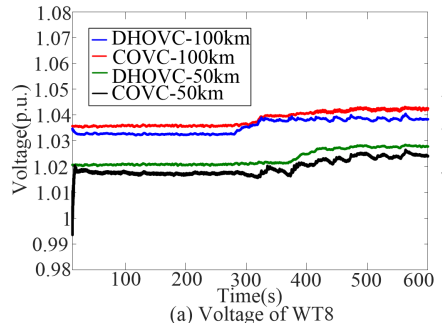

(a) Voltage of WT8

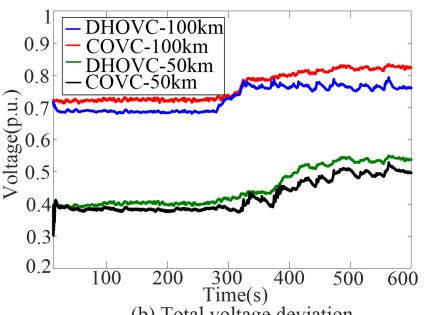

(b) Total voltage deviation

Fig. 15. Voltage of WT8 terminal bus and overall voltage deviation of the WF with $50 \mathrm{~km}$ and $100 \mathrm{~km}$ distance.

between the POC and VSC-HVDC system.
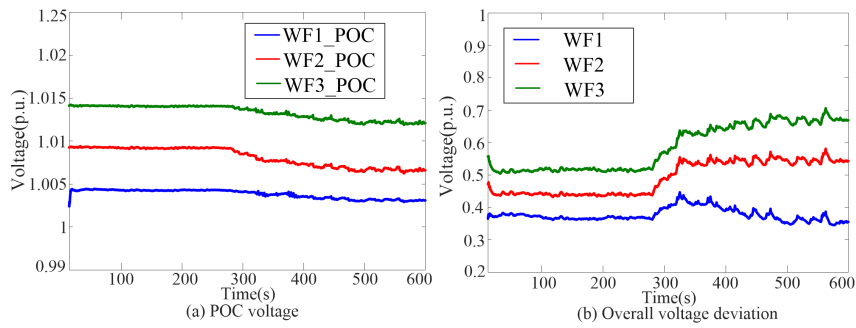

Fig. 16. POC and overall voltage deviation of the three WFs.

Fig. 17 shows the voltage performances of WT18, WT32 and POC under the three-phase-to-ground and single-phaseto-ground faults, respectively. In Fig.17(a), a three-phase-toground fault occurs at the MV bus1 from $13 \mathrm{~s}$ to $15 \mathrm{~s}$. At $13 \mathrm{~s}$, the fault point voltage drops to 0 p.u.. The voltages of WT18, WT32 and POC drop to around 0.66 p.u.. During the fault period, with the proposed DHOVC scheme, the voltage of WT32 terminal recovers to around 1 p.u. while the voltages of WT18 terminal and POC recover to around 0.93 p.u.. At $15 \mathrm{~s}$, the three-phase-to-ground fault is cleared. The voltages increase to around 1.32 p.u.. The voltages recover to the feasible range in $2 \mathrm{~s}$. The proposed DHOVC scheme realizes the high voltage and low voltage ride through for the WF under the three-phase-to-ground fault. In Fig.17(b), a singlephase-to-ground fault occurs at the WT23 terminal from $13 \mathrm{~s}$ to $15 \mathrm{~s}$, which is located at the end of the third feeder. Similar as Fig.17(a), the proposed DHOVC scheme realizes the high voltage and low voltage ride through for the WF under the single-phase-to-ground fault.
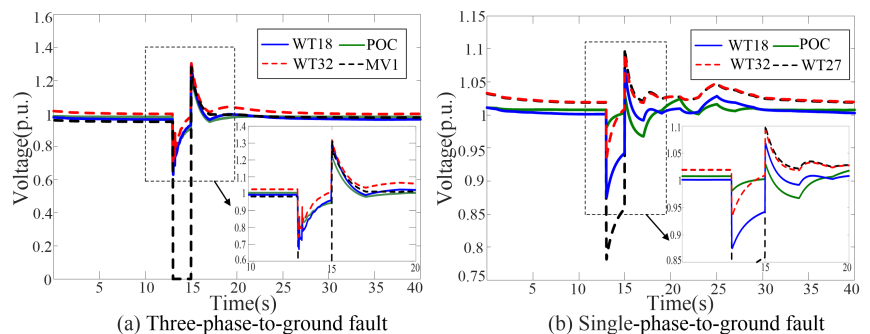

Fig. 17. Voltage of the WT18, WT32 and POC under faults.

\section{DISCUSSION}

The proposed DHOVC scheme uses a hierarchical control structure to achieve near-global optimal operation of WFs. It is shown that the DHOVC and COVC schemes can achieve excellent voltage/Var operation of the WF compared to the conventional PI control scheme. The control period of the DHOVC scheme is equal or larger than $2 \mathrm{~s}\left(N_{\mathrm{p}} \geq 2\right)$ while the control period of the COVC scheme is $1 \mathrm{~s}$. During a certain period, if the WF central controller with the COVC schemes is carried out $N$ times, the WF central controller with the DHOVC schemes only needs be carried out $N / N_{\mathrm{p}}$ times to achieve a similar voltage regulation performance while the communication time-delay events reducing to $N / N_{\mathrm{p}}$ times. With the ADMM algorithm, the scalability can be further improved. The large-scale constrained optimization problem is divided into an unconstrained QP problem and multiple parallel small-scale constrained optimization problems, which are solved in parallel. The calculation burden can be further reduced. The exchanged information between the central controller and WT local controller is local variables $\mathrm{x}$, global variables $\mathrm{z}$, and dual variables $\mathrm{y}$ instead of the actual measurements and references. The protection of the information privacy is improved. The WTs regulates Var output according to the optimized droop coefficients. During each control period, the response speed of the WTs to voltage fluctuations is accelerated and immune to the communication delay. When a communication failure occurs, each WT can regulate Var output according to the previously obtained droop coefficient, showing the better robustness and stability.

\section{CONCLUSION}

A DHOVC scheme based on MPC and ADMM methods is proposed in this paper for a VSC-HVDC connected offshore WF. The DHOVC scheme can reduce the voltage deviation of the POC, MV buses, and WT terminal from their nominal voltage while smoothing the Var fluctuations of the WTs. The central controller of the WF and local controllers are coordinated to generated an optimal voltage reference for the WFVSC and the optimal droop coefficients for the WTs during a certain predictive horizon. After obtaining the optimal droop coefficients, each WT can fast respond to the voltage fluctuations at their corresponding terminal and regulate Var output to achieve a near-global optimal performance during each predictive horizon. With the DHOVC scheme, the calculation burden of the central controller are reduced. Moreover, the DHOVC scheme can achieve uninterrupted operation of the WTs to improve the robustness and stability of the WF. The DHOVC scheme shows superiority on the voltage regulation for the VSC-HVDC connected WF.

\section{REFERENCES}

[1] M. A. Soliman, H. M. Hasanien, H. Z. Azazi, E. E. El-Kholy, and S. A. Mahmoud,"An adaptive fuzzy logic control strategy for performance enhancement of a grid-connected PMSG-based wind turbine," IEEE Trans. Ind. Informat., vol. 15, no. 6, pp. 3163-3173, June 2018.

[2] H. Zhao, J. Zhao, J. Qiu, G. Liang, and Z. Y. Dong, "Cooperative wind farm control with deep reinforcement learning and knowledge assisted learning," IEEE Trans. Ind. Informat., vol. 16, no. 11, pp. 6912-6921, Nov. 2020.

[3] T. H. Nguyen, K. Al Hosani, and M. S. El Moursi, "Alternating submodule configuration based MMCs with carrier-phase-shift modulation in HVDC systems for DC-fault ride-through capability," IEEE Trans. Ind. Informat., vol. 15, no. 9, pp. 5214-5224, Sept. 2019. 
[4] W. Wu, Y. Chen, L. Zhou, X. Zhou, L. Yang, Y. Dong, and A. Luo, “ A virtual phase-lead impedance stability control strategy for the maritime VSC-HVDC system," IEEE Trans. Ind. Informat., vol. 14, no. 12, pp. 5475-5486, Dec. 2018

[5] M. A. Cardiel-Alvarez, S. Arnaltes, J. L. Rodriguez-Amenedo, and A. Nami, "Decentralized control of offshore wind farms connected to diodebased HVDC links," IEEE Trans. Energy Conver, vol. 33, no. 3, pp. 1233-1241, Sep. 2018.

[6] W. Musial, S. Butterfield,and B. Ram, "Energy from offshore wind," (No. NREL/CP-500-39450). NREL, Golden, CO (US), 2006.

[7] S. Mensou, A. Essadki, T. N. B. B. Idrissi, "A direct power control of a DFIG based WECS during symmetrical voltage dips," Protect. and Contr. of Modern Power Syst., vol. 5, no. 1, pp. 36-47, 2020.

[8] Y. Guo, H. Gao, Q. Wu, H. Zhao, and J, Østergaard, "Enhanced voltage control of VSC-HVDC connected offshore wind farms based on model predictive control, "IEEE Trans. Sustain. Energy, vol. 9, no. 1, pp. 474487, Jan. 2018.

[9] S. Kevin, R. Sergi, and G. Oriol, "Analysis of reactive power strategies in HVDC-connected wind power plant clusters," Wind Energy, vol. 20, no. 12, pp. 1971-1982, 2017.

[10] Q. Zhou, Z. Tian, M. Shahidehpour, X. Liu, A. Abdulwhab, and A. M. Abusorrah, "Optimal consensus-based distributed control strategy for coordinated operation of networked microgrids," IEEE Trans. Power Syst., vol. 35, no. 3, pp. 2452-2462, May 2020.

[11] Q. Zhou, M. Shahidehpour, A. Paaso, S. Bahramirad, A. Abdulwhab, and A. M. Abusorrah, "Distributed control and communication strategies in networked microgrids," IEEE Commun. Surveys Tuts, vol. 22, no. 4, pp. 2586-2633, Fourthquarter, 2020.

[12] L. Yuan, K. Meng, and Z. Dong, "Hierarchical control scheme for coordinated reactive power regulation in clustered wind farms" IET Renewable Power Generation, vol. 12, no. 10, pp. 1119-1126, 2018.

[13] S. Huang, Q. Wu, Y. Guo, X. Chen, B. Zhou and C. Li, "Distributed voltage control based ADMM for large-scale wind farm cluster connected to VSC-HVDC," IEEE Trans. Sustain. Energy, vol. 11, no. 2, pp. 584594, Apr. 2020

[14] S. Huang, Q. Wu, J. Zhao, W. Liao, "Distributed optimal voltage control for VSC-HVDC connected large-scale wind farm cluster based on analytical target cascading method," IEEE Trans. Sustain. Energy, vol. 11 , no. 4, pp. 2152-2161, Oct. 2020

[15] H. R. Baghaee, M. Mirsalim, G. B. Gharehpetian, and H. A. Talebi, "A decentralized power management and sliding mode control strategy for hybrid AC/DC microgrids including renewable energy resources," IEEE Trans. Ind. Informat., 2017, in press.

[16] Y. Li, Z. Xu, J. Zhang, and K. Meng, "Variable droop voltage control for wind farm," IEEE Trans. Sustain. Energy, vol. 9, no. 1, pp. 491-493, Jan. 2017.

[17] H. Baghaee, M. Mirsalim, G. Gharehpetian, H. Talebi, "A generalized descriptor-system robust $H_{\infty}$ control of autonomous microgrids to improve small and large signal stability considering communication delays and load nonlinearities," Int. J. Electr. Power Energy Syst., vol. 92, pp. 63-82, 2017.

[18] J. Li, R. Xiong, Q. Yang, F. Liang, M. Zhang, and W. Yuan, "Design/test of a hybrid energy storage system for primary frequency control using a dynamic droop method in an isolated microgrid power system," Applied Energy, vol. 201, pp. 257-269, 2017.

[19] H. Mahmood, D. Michaelson, and J. Jiang, "Reactive power sharing in islanded microgrids using adaptive voltage droop control," IEEE Trans. Smart Grid, vol. 6, no. 6, pp. 3052-3060, Nov. 2015.

[20] M. Mokhtar, M. Marei, and A. El-Sattar, "An adaptive droop control scheme for DC microgrids integrating sliding mode voltage and current controlled boost converters," IEEE Trans. Smart Grid, vol. 10, no. 2, pp. 1685-1693, Mar. 2019.

[21] J. Duan, H. Xu, W. Liu, J. Peng, and H. Jiang, "Zero-sum game based cooperative control for onboard pulsed power load accommodation," IEEE Trans. Ind. Informat., vol. 16, no. 1, pp. 238-247, Mar. 2020.

[22] C. Wang, J. Duan, B. Fan, Q. Yang, and W. Liu, "Decentralized highperformance control of DC microgrids," IEEE Trans. Smart Grid, vol. 10, no. 3, pp. 3355-3363, May 2020.

[23] S. Magnússon, G. Qu, and N. Li, "Distributed voltage control with communication delays," arXiv preprint arXiv:1903.01065, 2019.

[24] G. Cavraro, S. Bolognani, R. Carli, and S. Zampieri, "The value of communication in the voltage regulation problem," in proc. 54th IEEE Conf. Decis. and Cont. (CDC), 2016.

[25] J. Martínez, P. C. Kjær, and R. Teodorescu, "DFIG turbine representation for small signal voltage control studies," in proc. 12th Int. Conf. on Optimization of Electri. and Elect. Equip., IEEE, pp. 31-40. May 2010.
[26] J. M. Maciejowski, Predictive control: with constraints, Pearson education, 2002.

[27] K. Christakou, J. LeBoudec, M. Paolone, and D. C. Tomozei, "Efficient computation of sensitivity coefficients of node voltages and line currents in unbalanced radial electrical distribution networks," IEEE Trans. Smart Grid, vol. 4, no. 2, pp. 741-750, June 2013

[28] E. D. Sontag, "On the input-to-state stability property," Syst. Control Lett., vol. 24, pp. 351-359, 1995.

[29] B. A. Robbins, C. N. Hadjicostis, and A. D. Domínguez-García"A twoStage distributed architecture for voltage control in power distribution systems," IEEE Trans. Power Syst., vol. 28, no. 2, pp. 1470-1482, May 2013

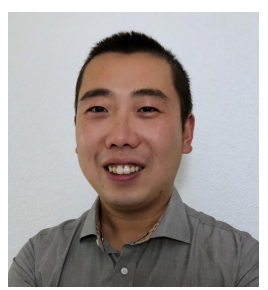

Sheng Huang received the M.S. and Ph.D. degree both in College of Electrical and Information Engineering, Hunan University, Changsha, China, in 2012 and 2016, respectively. He was a Postdoc with the Center for Electric Power and Energy, Technical University of Denmark from 2017 to 2021 . He is currently a teacher with the College of Electrical and information engineering, Hunan University, China. His research interests include renewable energy generation, modeling and integration study of wind power, control of energy storage system, voltage control, generator and motor control

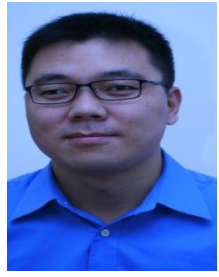

Qiuwei Wu(M,08-SM'15) obtained the PhD degree in Power System Engineering from Nanyang Technological University, Singapore, in 2009.

$\mathrm{He}$ was a senior R\&D engineer with VESTAS Technology R\&D Singapore Pte Ltd from Mar. 2008 to Oct. 2009. He has been working at Department of Electrical Engineering, Technical University of Denmark (DTU) since Nov. 2009 (PostDoc Nov. 2009-Oct. 2010, Assistant Professor Nov. 2010-Aug. 2013, Associate Professor since Sept. 2013). He was a visiting scholar at Department of Industrial Engineering \& Operations Research (IEOR), University of California, Berkeley, from Feb. 2012 to May 2012 funded by the Danish Agency for Science, Technology and Innovation (DASTI), Denmark. He was a visiting professor named by Y. Xue, an Academician of Chinese Academy of Engineering, at Shandong University, China, from Nov. 2015 to Oct. 2017. He was a visiting scholar at the Harvard China Project, School of Engineering and Applied Sciences, Harvard University from Nov. 2017 - Oct. 2018 funded by the Otto Mønsted Fond.

His research interests are operation and control of power systems with high penetration of renewables, including wind power modelling and control, active distribution networks, and operation of integrated energy systems. He is an Editor of IEEE Transactions on Smart Grid and IEEE Power Engineering Letters. He is also an Associate Editor of International Journal of Electrical Power and Energy Systems, and Journal of Modern Power Systems and Clean Energy. He is a subject editor for IET Generation, Transmission \& Distribution, and IET Renewable Power Generation.

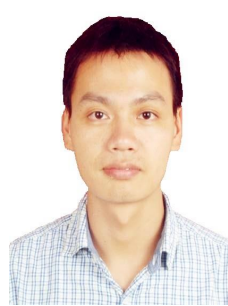

Wu Liao received the B.Sc. degree in automation in 2010 from Hunan University, Changsha, China, and the Ph.D. degree in electrical engineering from Hunan University, Changsha, in 2016. He was with CRRC Zhuzhou Institute Co., Ltd., Zhuzhou, China, as a converter software designer and researcher between 2016 and 2019 . He is currently with Hunan University as a Postdoctoral Researcher at the Department of Electrical Engineering. His research interests include wind power generation, modular multilevel converters, high power motor drives. 


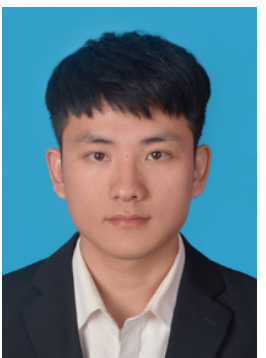

Gongping Wu was born in Jiangxi, China. He received the B.S. degree from Jinggangshan University, Jiangxi, China, in 2014, and the M.S. degree from the Hunan University of Technology, Hunan, China, in 2017, both in electrical engineering and automation. He studied at Tongji University, Shanghai, China, from September 2011 to September 2013. Since September 2017, he has been working toward the $\mathrm{Ph} . \mathrm{D}$. degree at the College of Electrical and Information Engineering, Hunan University, Changsha, China. During 2019-2021, he was a visiting student in the Department of Electrical Engineering, Technical University of Denmark, Kgs. Lyngby, Denmark. His current research interests include permanent magnet synchronous motor servosystems, predictive current control, and wind energy conversion system.

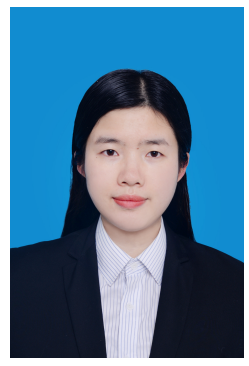

Xueping Li was born in Hunan, China, in 1993. She received the B.S. degree in automation from Xiangtan University, Xiangtan, China, in 2015, and the M.S. degree in electrical engineering from Hunan University, Changsha, China, in 2018. She is currently pursuing the Ph.D. degree in electrical engineering from the College of Electrical and Information Engineering, Hunan University, Changsha. Her research interests include wind power generation, wind farm optimization.

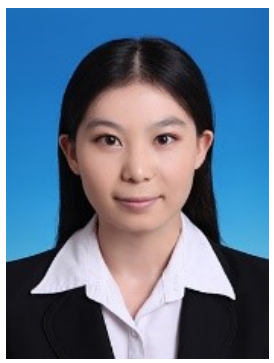

Juan Wei received the B.S. and M.S. degrees in electrical engineering from the North China Electric Power University, Beijing, China, in 2011 and 2014, respectively. She is currently pursuing the $\mathrm{Ph} . \mathrm{D}$. degree in electrical engineering from Hunan University, Changsha, China. She was a visiting student at the Department of Electrical Engineering, Technical University of Denmark, Denmark. Her research interests include wind power modeling and control, renewable energy generation and power system economic and secure operation. 